\title{
ENTREVISTA CON EL DR. JOSÉ ANTONIO FERNÁNDEZ MOLINA DR. JOSÉ ANTONIO FERNÁNDEZ MOLINA INTERVIEW WITH
}

\author{
Héctor Lindo Fuentes* \\ Ana Yolanda Zúniga Arias ${ }^{* *}$
}

\begin{abstract}
Resumen: Entrevista realizada al Dr. José Antonio Fernández Molina con el objetivo de exponer el desarrollo historiográfico en Centroamérica, en la voz de uno de sus máximos representantes y acuciosos críticos. Además, interesa conocer cómo se inició este historiador y los diferentes procesos que enfrentó en su formación y en el ejercicio de su quehacer académico. Participan en la entrevista, el Dr. Héctor Lindo Fuentes y la MSc. Ana Yolanda Zúñiga Arias.
\end{abstract}

Palabras claves: entrevista; historia; historiografía; Centroamérica; Costa Rica; José Antonio Fernández Molina.

\begin{abstract}
Interview with Dr. José Antonio Fernández Molina, with the objective to expose the historiographic development in Central America, in the voice of one of its maximum representatives and diligent critics. Also, it's of the utmost interest knowing how this historian got started and the different processes which his formation faced, and the exercise of his academic craft. Participating in this interview are Dr. Héctor Lindo Fuentes and MSc. Ana Yolanda Zúñiga Arias.
\end{abstract}

Keywords: Interview; History; Historiography; Central America; Costa Rica; José Antonio Fernández Molina.

Fecha de recepción: 25/01/2019 - Fecha de aceptación: 28/03/2019

* Salvadoreño. Doctor en Historia de la Universidad de Chicago. Ha trabajado temáticas sobre economía en América Latina, educación y sobre memoria política de El Salvador. Ha sido catedrático en varias universidades de los Estados Unidos de América. Correo electrónico: lindo@fordham.edu

** Costarricense. Máster en Historia Aplicada y catedrática de la Universidad Nacional (UNA), Costa Rica. Actual directora de la Escuela de Historia de la UNA. Correo electrónico: yolanda.zuniga.arias@una.cr 


\section{Presentación ${ }^{1}$}

La Revista de Historia en esta ocasión ha decidido entrevistar al Dr. José Antonio Fernández Molina con el objetivo de exponer el desarrollo historiográfico en Centroamérica, en la voz de uno de sus máximos representantes y acuciosos críticos. Además, interesa conocer cómo se inició este historiador y los diferentes procesos que enfrentó en su formación y en el ejercicio de quehacer académico. Participan en la entrevista, el Dr. Héctor Lindo y la MSc. Ana Yolanda Zúñiga Arias.

El Dr. Fernández Molina es un catedrático jubilado de la Universidad Nacional, laboró desde los inicios de la Escuela de Historia hasta su jubilación, aunque sigue teniendo vínculos con la unidad. Se desempeñó como docente, investigador y estuvo en varios períodos como director de la Unidad Académica. En sus publicaciones se encuentran estudios específicos de Guatemala, El Salvador, Costa Rica y Centroamérica en general y se ubican en el período colonial y el siglo XIX. Versan acerca de temáticas relacionadas con el comercio colonial y procesos sociopolíticos. En la docencia impartió cursos de historia de América Latina y Centroamérica en los diferentes períodos, desde la colonia hasta los siglos XIX y XX. Por último, es necesario indicar que es un destacado intelectual reconocido en América Central y referente obligatorio para quienes estudian la historia centroamericana.

Revista de Historia (RH): Dr. Fernández, es un gusto tener ocasión de conversar con usted y conocer detalles de sus inicios, trayectoria profesional y proyectos. ¿Cómo fue que encontró su vocación de cientista social e historiador? ¿Fue cuestión de vocación innata, entorno social o lectura? ¿Qué nos puede decir al respecto?

José Antonio Fernández Molina (JAFM): Esa es una cosa difícil de responder siempre, porque nadie es tan consciente de por qué es lo que es. Yo viví en un entorno lleno de libros, porque a pesar de que mi padre únicamente tuvo tres años de primaria, fue un lector consumado junto con mi madre. Creo que esa fue la forma en que él superó la frustración de no haber podido estudiar. En el momento en que le dijo a mi abuelo que quería estudiar, este que creía que tener hijos era criar peones, le contestó que, "primero está la obligación y después la devoción", o sea, que ni haciéndose cura era aceptable dejar de ser peón.

La lectura, por supuesto, no era únicamente sobre temáticas históricas: había muchas biografías y muchas novelas, pero estaban también los Episodios nacionales de Benito Pérez Galdós, que ellos leyeron completos conmigo en

1 Agradecimiento a los estudiantes asistentes que colaboraron en la realización de esta entrevista, Dalia Rebeca Arce Aguirre, estudiante de la Maestría en Historia Aplicada de la Universidad Nacional y Andrey Monge Araya, licenciado en Enseñanza de Estudios Sociales y Cívica de la Universidad Nacional. 
medio. Eso me proporcionó una capacidad de imaginación increíble ante todas las descripciones de la historia española que el autor hacía. Ahí me comenzaron a interesar los libros, y la lectura se convirtió en una moneda de cambio muy útil con mis coetáneos, es decir, mis primos y mis amigos que no leían. Por ello, cuando yo había leído y sabía algo, tenía un recurso del que ellos carecían, una capacidad de imaginación para organizarlos en juegos para hacer lo que yo quería. Seamos francos, más bien lo que yo podía hacer, porque yo no podía jugar futbol ni otras cosas que exigían destreza física, pero organizaba entonces los juegos y la diversión según lo que me inspiraba la lectura. Desde ese punto de vista, la lectura es una cosa que desde pequeño fui absorbiendo y aprovechando en múltiples sentidos. El leer mucho y comprender cosas.

Para complicar el asunto, tenía un tío que era la "oveja roja" de la familia. El único de izquierda, que con su esposa mexicana, a quien le dije tía mientras vivió, a pesar de que mi tío se casó otras tres veces, me comenzaron a dar una visión más crítica de la realidad, y por lo tanto, del pasado también. Esa visión más crítica, la comencé a absorber como a los 12 o 13 años, y por supuesto yo percibía que no era una cuestión muy popular dentro de la familia, pero eso justamente lo hacía en cierto sentido muy atractivo. Este era el más joven de mis tíos y había sido un gran compañero mío durante la niñez; su influencia fue clave porque comencé a ser un poco más analítico de lo que leía. Un poco nada más, lo que se puede esperar de un adolescente con inquietudes.

A lo antes dicho, debe añadirse que yo tenía acceso a lo que publicaba la Academia de Geografía e Historia de Costa Rica, porque don Jorge Lines, uno de sus miembros, estaba casado con una prima de mi mamá; yo recibía algunos libros que por cierto me parecían aburridísimos -sobre el 400 aniversario de la fundación de Cartago o cosas así- que estaban escritos de una manera muy lineal. Pero también, tenía acceso a las Revistas de los Archivos Nacionales que incluían reproducciones de documentos y eso sí me gustaba más, porque no te daban un argumento, te daban varios argumentos: podía haber un documento en que estaba lo que decía el gobernador, lo que decía el acusado, lo que decían los testigos, y uno comenzaba a jugar de juez. Por supuesto que debo confesar que muchísimas cosas no las entendía, había mucho vocabulario que aprendí después, o bien, tuve que buscar en su momento los significados.

Yo creo que sabía que iba a ser historiador a los 14 años. No estaba muy seguro qué era exactamente eso, pero yo sabía a esa edad que iba a ser historiador, y hubo al respecto tal vez dos cosas que me empujaron, además de todo lo que antes dije. A los 13 años, una maestra de la escuela de la que yo me gradué de primaria me pidió que organizara una charla sobre los zambos mosquitos, no sé bien por qué, para unos mocosos de 11 años. Yo me lo agarré en serio. Todo lo que había en Cartago sobre los zambos mosquitos -que no pudo haber sido mucho- me lo leí; organicé la charla, hice mapas, y les hablé de fechas y cosas 
sobre las cuales los chiquillos ni tenían idea. Saber qué era y por qué es diferente el siglo XVII, ciertamente no es cosa que se le ocurra a un chiquito de 11 años. Y esa fue mi primera experiencia de enseñar, que sinceramente me gustó.

Después fui parte de una organización de universitarios -yo metido a grande porque tenía 16 años y no había siquiera salido del colegio- que se llamaba el Forum Estudiantil Cartaginés, y que había organizado Roberto Murillo, un doctor en filosofia, profesor de la Universidad de Costa Rica. Creo que era el segundo que organizaba, porque existió uno en los años 1950, y este ya fue en los años 1960. Una vez más, ahí teníamos que dar conferencias, cada cierto tiempo, nos íbamos turnando en impartir las conferencias, pero tenían que ser conferencias que fueran atractivas a todos, por un lado, y que estuvieran aportando algo. Una vez más, me gustó. Me gustó exponer, me gustó organizar, me gustó plantear.

Entonces, vocación, formación, no sé, yo creo que la cultura libresca me llevó a eso. A la hora de escoger y decidir finalmente, a mí ahora me llama la atención que siempre me dijeron mis maestros que yo tenía que ser abogado, pero lo deseché por un malentendido prurito, de, ¿cómo decirlo?, por el supuesto de que yo no podría defender a un culpable, o sea, una gran incomprensión acerca de cómo funciona la justicia. El limitado repertorio de opciones que valoraba fue reduciéndose a historia estrictamente, y esto fue lo que decidí que quería estudiar cuando entrara a la universidad. No enfrenté ninguna oposición dentro de mi familia, más bien al contrario, porque los libros que yo leía, se los leía de paso mi papá. No sé si respondí a la pregunta, porque ciertamente su sentido es difícil de precisar.

RH: Más allá de responderla, lo que refiere es casi como una historia conmovedora, acerca de cómo se van abriendo los ojos de un niño a una realidad diferente. Resulta interesantísimo, en lo que atañe a cómo se impone una responsabilidad de ser maestro, y de cómo puede uno ir abriendo los ojos a otras realidades. Todo esto se vincula con la siguiente pregunta, que es justamente sobre las figuras y teorías que fueron especialmente influyentes en los primeros años de formación profesional, es decir, cuando ya usted decidió ser historiador, porque hay también otras influencias, ya sea de individuos o de formas de ver las cosas, que abren otras ventanas o perspectivas.

JAFM: En la Revista de Historia que se le dedicó como homenaje póstumo a Ciro Cardoso, ${ }^{2}$ hice una reflexión sobre cómo era la Universidad de Costa

2 Véase, José Antonio Fernández Molina, "Homenaje tardío al maestro Ciro F. Santana Cardoso", Revista de Historia (Costa Rica) 68 (julio-diciembre, 2013): 23-26, en: http://www.revistas.una.ac.cr/index.php/ historia/article/view/6495 
Rica en los tiempos en que ingresé. Era un gran colegio, había muy pocos libros, muy poca posibilidad de lectura, no existían las fotocopiadoras, todo tenía que ser pasado a esténcil para después crear antologías. Muy limitado en ese sentido, pero al mismo tiempo se estaba dando la gran explosión marxista, y la llamo "la gran explosión" porque había tantos grupos como personas. Por supuesto que dependía de a quién le preguntabas, pero a modo de caricatura me imagino que los "troskos" dirían que el entorno parecía anarquista y estos últimos dirían que parecía trotskista. Cada uno tenía su versión de marxismo y cómo entenderlo para la sociedad costarricense; esa generación fue muy combativa, muy crítica, pero el marxismo no aterrizaba en las aulas universitarias de una manera organizada. La gente leyó por su cuenta, fue sacando las consecuencias individuales o colectivas, hasta que llegaron Héctor Pérez y Ciro Cardoso.

Con Héctor y Ciro, a partir de lo que había sido la evolución de la Escuela de los Annales, de un momento a otro los horizontes como que explotaron. Yo recuerdo una conversación que tuve en mis primeros años en la Universidad de Costa Rica, en que dos compañeras muy bien intencionadas, me dijeron: "Tenés que terminar rápido", y yo les pregunté que a qué se debía la urgencia, y sin mucho pensarlo me contestaron simplemente: "Es que se están acabando los presidentes". Lo típico por entonces era hacer las tesis sobre, por ejemplo, la Administración de Alfredo González Flores, o bien, la segunda administración del presidente fulano de tal..., o sea, era una historia de administraciones públicas. Yo ahora las leo y pienso ipobrecitos los lectores! ¡Qué cosa más aburrida! Porque era una lista de cosas y no había argumento explicativo detrás. Así las cosas, en la visión de esos años, yo tenía que apurarme y terminar rápido, pues si otros escogían los últimos presidentes ¿de qué iba a hacer la tesis?

Después de que llevé el curso de métodos y técnicas con Ciro Cardoso, en el que todo era medible, todo se podía problematizar, desde cosas tan sencillas como la reproducción humana, la muerte, el matrimonio -digamos la nueva historia demográfica- y la historia económica, se potenció entonces lo que yo quería estudiar de una manera increíble. Eso fue en mi último año en la Universidad de Costa Rica. Habíamos tenido profesores tradicionales a lo largo de toda la carrera, entonces ellos llegaron e hicieron la ruptura. Y esa ruptura es con la que yo me identifiqué, y con la que llegué al doctorado, pero no sé si hablar de eso rebasa el sentido esencial de la pregunta.

RH: Pues nos resulta todo tan interesante que casi que le invitaríamos a hablar a sus anchas sobre eso.

JAFM: La experiencia del doctorado fue muy enriquecedora en muchos sentidos. En primer lugar, por el contacto con gente como Magnus Mörner, 
Richard Graham, Eric Van Young y Carolyn Boyd, una hispanista. Ellos usaban mucho la teoría, pero con sentido práctico, es decir, la teoría que me sirve para explicar algo. Yo venía de un contexto en que habíamos tomado la teoría casi como religión, y eso es definitivamente un problema. Con ellos aprendí mucho. Por otro lado, me pareció increíble que existieran tantos libros sobre América Latina, como había en la Benson Latin American Collection: yo no podía creer que me hubieran formado en la Universidad de Costa Rica y que yo hubiera dado clases en la Universidad Nacional, con la diezmilésima parte de los libros de historia que tienen ahí.

Fueron también muy enriquecedores, los seminarios en que uno confrontaba con gente de todo lado. Había cubanos, canadienses, de toda América del Sur, y hasta un ruso tuve de compañero. Era gente que traía un bagaje cultural, una manera de ver las cosas y un proyecto de vida muy diferente; y eso se reflejaba en cómo interpretaban lo que leíamos. A mí me sorprendía lo que lograban ver, porque tal vez la compañera era antropóloga o era originalmente socióloga, entonces un mismo libro, una misma lectura adquiría una riqueza increíble. Los seminarios fueron todo un proceso muy, muy interesante.

Pero la referencia formativa realmente sorprendente, fue la de la elaboración de la tesis, porque me obligó no solamente a conocer en el pasado una realidad sobre la que tenía muy pocos elementos, sino que me obligó a trabajar en otra realidad totalmente diferente, que era la de Guatemala en medio de la Guerra Civil, además de visitar Nicaragua cuando los contrarrevolucionarios procuraban acabar con la Revolución Sandinista. La tesis me centroamericanizó en muchos sentidos.

Yo no sé si puedo decir que hay una teoría específica que me ha marcado, tiendo a ser muy materialista en el buen sentido del término. Soy alérgico a los idealismos, pero tampoco creo que me conforme con la visión estrictamente marxista, por lo menos tradicional o cuadrada llamémosle.

RH: Ya que se mencionó el tema de la crisis regional de los años 1980, nos viene la pregunta de si los conflictos de esa década tuvieron un impacto importante en la intelectualidad centroamericana. ¿De qué forma cree usted que afectaron a los historiadores y las historiadoras?

JAFM: Esta es una pregunta muy difícil, pues yo tengo vivencias de cómo eran Guatemala y Costa Rica. En la década de 1980, realicé una visita de un día a la Universidad de El Salvador y en Nicaragua estuve básicamente en León. Yo creo que la crisis de los años ochenta fue el momento en que se abrió, ya con más fuerza, la apertura de la comunidad de historiadores, pero fue una década terrible. Ese decenio no es en sentido estricto "la década perdida". Es una 
década maldita, es la verdad. Es una década maldita, porque si uno se pone a pensar, lo único que quedó de ese funesto período de conflicto fue la Revolución Sandinista, y ya ni eso quedó, porque lo que tenemos ahora es un somozismo con otro apellido. Pese a otra gran cantidad de cosas que lamentar, para mí en cierto sentido, ahí comienzan a consolidarse muchísimas cosas de lo que sería después la comunidad centroamericana de historiadores.

RH: Bueno, eso nos lleva a la siguiente pregunta, sobre el cierre de esa década de 1980, cuando se empezó a hablar de la historia general de Centroamérica. Por ese tiempo nos reunimos todos, que era un momento como de esperanza, de construcción, y empezamos a ser testigos de un proceso de profesionalización y transnacionalización de los estudios históricos. ¿Cómo ve usted a la distancia ese proceso de profesionalización? ¿Cómo podemos seguir caminando en esa dirección?

JAFM: Voy a dar dos respuestas a tu pregunta. Estoy de acuerdo en lo relativo a la profesionalización, pero no estoy de acuerdo en lo de la regionalización. Me explico. Con excepción de la Historia General de Centroamérica, que es una obra de síntesis, seguimos haciendo historias fundamentalmente nacionales. No hay comparaciones ni confrontaciones que consideren la reconstrucción y explicación de un proceso en dos o tres países. Podría argumentarse que eso tiene que ver con las posibilidades de quienes viven en el Primer Mundo, muy diferentes de quienes viven en el Cuarto Mundo, pero incluso investigadores que vienen con financiamiento revelan esa situación particular de segmentación y concentración a nivel nacional en el enfoque. Se me viene a la memoria el caso de Lowell Gudmundson. Él primero estudió Costa Rica, después Guatemala, y eventualmente a partir de sus trabajos realizó una comparación, pero ese análisis comparativo, no se pudo hacer en el mismo año.

En términos generales, la perspectiva no ha sido tan centroamericana como quisiéramos que fuera en realidad. Somos centroamericanos en el mismo sentido que la Organización de Estados Centroamericanos (ODECA), juntamos a centroamericanos, pero no estamos haciendo proyectos a nivel centroamericano. Eso se debe, primero a que no tenemos quizás los recursos necesarios, pero segundo a que somos terriblemente individualistas. El individualismo es rampante en esta profesión y región. Con las facilidades de comunicación que hay ahora, con todas las cosas que se han puesto en línea por bibliotecas y archivos, no se explica cómo es posible que no haya, tal vez no gente de mi generación, pero sí muchachos más jóvenes trabajando aspectos que tengan que ver con el bicentenario de la independencia, para presentar nuevas visiones de conjunto o comparadas sobre este proceso. 
El trabajar en grupo, el trabajar en equipo es algo que no se estila. Si a nosotros nos hubieran dado los mismos millones que recibió el Proyecto Manhattan para hacer la bomba atómica hubiéramos terminado haciendo un montón de bombitas, pero de esas que se tiran el 31 de diciembre, porque no hubiéramos sido capaces de desarrollar lo que se necesita para un trabajo de grupo. Esa es, desgraciadamente, nuestra realidad.

A pesar de ello, tuvimos suerte, porque si se piensa detenidamente, la crisis de los años 1980 generó cosas que después ayudaron a unirnos como comunidad por más multi en lugar de transnacional que sea. Por ejemplo, se da la fundación del Centro de Investigaciones Regionales de Mesoamérica (CIRMA), que comienza a publicar Mesoamérica; viene una cantidad significativa de europeos y norteamericanos a hacer investigaciones de todas las calidades -había libros que eran una colección de fotografías sin ningún arte ni concierto y que en cierto sentido eran únicamente propaganda-, pero hubo también estudios muy importantes.

Por otro lado, comienza un proceso de fortalecimiento de la formación profesional mediante la obtención de doctorados por muchos académicos. Eso tuvo que ver mucho con la iniciativa individual, y algo con una cierta madurez profesional. Digo que más con lo individual porque eso no fue planeado, no fue que las universidades dispusieron de forma consciente y planificada sobre esto. No dijeron quiénes iban a doctorarse y en qué orden. Quien no quiso no lo hizo, quien quiso buscó la beca y buscó la admisión en un determinado programa. Las instituciones tuvieron poco que ver.

Además, comenzaron a crearse espacios de confrontación de ideas. El Primer Congreso Centroamericano de Historia Demográfica, Económica y Social que organizó el Consejo Superior Universitario Centroamericano (CSUCA), después vinieron los simposios sobre historia agraria e historia del café que organizó Mario Samper, después los Congresos Centroamericanos a partir de 1992. Tan importante como estos espacios de discusión fue la aparición de medios de publicación periódica. También en este campo el CSUCA fue pionero con la creación de la Revista de Estudios Sociales Centroamericanos, seguida de la aparición de la Revista de Historia que fundó el Dr. Germán Tjarks en 1975. Después aparecieron otras publicaciones como Mesoamérica -editada por el CIRMA, un centro de investigación financiado con fondos privados-, el Anuario de Estudios Centroamericanos, la Revista de Historia publicada por el Instituto de Historia de Nicaragua y Centroamérica; y comienza a publicarse Diálogos: Revista Electrónica de Historia. Aparecieron muchas publicaciones a las que no me voy a referir porque fueron colecciones de uno o dos números, y nunca más volvieron a salir. No hemos entrado de lleno a la publicación en medios digitales, pero creo que razones de costos eventualmente nos forzarán a ello. Por último, aparecieron varios programas de posgrado en Centroamérica, varios fallidos porque creo 
que eran más de los que permitían las capacidades de las instituciones y los que requerían las sociedades del istmo, los historiadores que necesitamos.

Todo eso quizá hubiera sido diferente si no hubiéramos tenido la crisis de la década de 1980. Esta coyuntura no causó de forma directa las cosas, pero sí condicionó los procesos. Ese momento de esperanza de 1992, como plantean en su pregunta, no lo fue a nivel de los presupuestos universitarios costarricenses, pues las universidades de Costa Rica siguieron en crisis económica toda la década de 1990. Resulta significativo que ante la crisis cada uno de nosotros tuvo una posición política diferente ante lo que sucedió, pero que no comentábamos. Lo hemos dejado de lado, no sé si por instinto de supervivencia o porque es una cosa que se volvió secundaria. No es algo de lo que pueda hablar con propiedad pues hay mucho que ignoro; yo sé que hubo hondureños que fueron a estudiar a Europa en las décadas de 1980 y 1990, pero hasta donde sé no ha habido una recomposición del personal de la Escuela de Historia de la Universidad Nacional Autónoma de Honduras. No conozco ningún estudio exhaustivo, para determinar el impacto provocado por la crisis en la educación superior de la región.

RH: ¿Cómo ha sido la producción académica de historiadores centroamericanos en las últimas décadas?

JAFM: Me parece que deberíamos partir del principio, de que cada generación contribuirá al acerbo historiográfico, a partir de las preocupaciones de su presente. Por ello, aunque aún estemos vivos la mayoría de quienes nos identificamos con la nueva historia, ya hay quienes explícita o implícitamente se identifican con la novísima e incluso "novisísima" historia, una suerte de remedo de lo que pasó con la Recopilación de Leyes de Indias. Antes de referirme a las últimas décadas, me parece justo reconocer que, aun antes del despegue provocado por la influencia de la Escuela de los Annales, ya había signos que presagiaban un cambio de la historia político-institucional que predominaba en las tesis de grado costarricenses. En efecto, fue precedida por el estudio de Murdo MacLeod sobre los primeros siglos del coloniaje, los de Severo Martínez Peláez sobre ese mismo período, análisis más comprensivos sobre instituciones como la Factoría de Tabacos en Costa Rica, el trabajo sobre el Partido Reformista o el primer estudio sobre la llamada Revolución de 1948 costarricense. Los que eran costarricenses nunca llegaron a identificarse como una generación -sospecho que, por motivos político-partidistas, pero es un aspecto por analizar-y en otros países de la región la interpretación del pasado justificaba la estrategia de los distintos grupos revolucionarios, así que tampoco podía consolidarse un sentido de generación. 
¿De qué partió la nueva historia? Permítaseme señalar dos características: un idealismo que tendía a fortalecer la identidad nacional y un predominio de estudios sobre hombres importantes -algunos no llegaban a "grandes hombres"en los trabajos de graduación. Entre los trabajos que tendían a fortalecer la ideología recuerdo uno de la década de 1970, cuya tesis era que la excepcionalidad costarricense se explicaba por la educación; el motto del país con más maestros que soldados debía aplicarse desde 1840. El estudio de hombres importantes resulta obvio en cualquiera de las tesis sobre períodos presidenciales que mencioné antes, que tenían una capacidad de imaginación igual a cero. Básicamente era tomar los tomos correspondientes de la Colección de Leyes y Decretos de la República de Costa Rica, limitarse a transcribir o parafrasear, sin ver qué sentido o significados tuvo en el mediano y largo plazos.

Estas dinámicas contrastan con la que rige ahora: los trabajos de ahora son muchísimo mejores. Indudablemente. Yo puedo tener discrepancias con muchos y posiblemente con casi todos los libros o artículos en uno o dos aspectos, pero son cosas planteadas que no tienen el nivel de idealismo de los artículos de principio de los años 1970.

No presumo de conocer toda la producción historiográfica centroamericana, pero, para no hablar solo de Costa Rica, pongo de ejemplo lo que conozco que han hecho los muchachos de la Licenciatura en Historia de El Salvador y es de quitarse el sombrero. Son una mezcla de buena imaginación, planteamiento y redacción. Es cierto que, en el Primer Seminario de Historia Demográfica, Económica y Social se presentaron cosas novedosas, pero ya éramos un poco mayores; estos muchachos definitivamente tienen mayor capacidad analítica, de problematizar y de buscar fuentes para responder. Me los he encontrado en el Archivo General de Centroamérica, Guatemala, ampliando un aspecto u otro.

RH: Esa es una visión optimista sobre la carrera de historia en Centroamérica, sobre los historiadores y la producción histórica que puede venir a futuro. ¿Puede ampliar sobre esa proyección a futuro y sobre la incidencia social que podría tener esta nueva figura social del historiador?

JAFM: Yo creo que definitivamente lo que se está produciendo es muchísimo mejor, incluso como literatura, que lo que producíamos nosotros en mi generación a su misma edad. El problema fundamental es que hay una gran desigualdad de país a país, de la misma manera que puedo decir que quedo muy impresionado con los salvadoreños y algunos guatemaltecos, con toda honestidad conozco poco de los hondureños, y casi nada del posgrado abierto en Nicaragua.

En términos generales soy positivo; yo creo que, gracias a la Revolución Tecnológica, los muchachos van a tener herramientas que ni nos imaginamos, 
porque la circulación de libros digitales ha aumentado de manera exponencial y también la cantidad de fuentes que suben a la web es muy grande. En mi generación se pasó de antes de la fotocopiadora al momento en que ya no hay papel.

Tengo mucha esperanza en que va a ser una generación propositiva muy interesante. Políticamente es complejo saber hacia dónde se orientarán, acaso por la incomprensión que provoca el salto intergeneracional. Yo tenía la impresión de que lo único que los jóvenes sabían hacer era estar pegados al teléfono; ahora los de El Salvador han demostrado lo contrario, tenían algo más qué hacer que hablar por teléfono. Está por verse cómo se va a traducir eso en su capacidad creativa, en lo que van a investigar. Creo que es tan difícil para mí hacer una evaluación en este momento, como hubiera sido para cualquiera de mis profesores imaginarse lo que se estaría haciendo hoy en Costa Rica. En ese sentido, yo tengo un poco menos de fe en la capacidad propositiva que mi colega Mario Samper, quien sí creía que el pasado podía ayudar a avizorar soluciones para el futuro. Mi conclusión es que si las sociedades fueran tan ordenadas los historiadores deberíamos ser jefes de Estado, en lugar de ser los filósofos como dijeron los antiguos griegos.

RH: En la década de los años 1990, algunos historiadores se interesaron en la producción de textos escolares con la esperanza de incidir en la calidad de la educación y de la memoria histórica. ¿Cuáles cree usted que son los mejores vehículos, para que quienes practicamos la historia contribuyamos de una manera constructiva en los grandes debates nacionales en Centroamérica?

JAFM: Aclaremos algo para no enredarnos y porque no quiero entrar en conflicto con un grupo de colegas que se dedica a eso. Los textos que se hicieron en la década de 1990 no tenían nada que ver con memoria histórica como se le entiende hoy. Creo que deseábamos que los alumnos adquirieran cierta conciencia histórica, pero no memoria histórica que se estudia y plantea diferente. Dicho esto, una vez más excluyendo la Historia General de Centroamérica que no estaba pensada para primaria ni secundaria, el problema es que no hemos resuelto cómo incidir realmente en la educación sobre el pasado en nuestros países por razones institucionales y de diseño del medio de transmisión.

Se me viene a la mente un texto sobre historia de Centroamérica y Panamá que coordinó Víctor Hugo Acuña, en que participamos varios colegas de todos los países. Pues una vez impreso el mismo Ministerio de Educación de Costa Rica se encargó de embodegar los textos durante años para que no llegaran a los estudiantes. Nuestra pretensión era que los estudiantes de todos los países tuvieran una visión ístmica más que centroamericana, pero cuando quienes están a 
cargo de diseñar la política de cada país no están de acuerdo, no se hace y punto. Yo creo que nunca salieron de bodega en el caso costarricense.

Esto tiene que ver con la institucionalidad misma, pues, sin entrar a discutir quiénes y cómo definen los contenidos en cada uno de los países, me atrevo a asegurar que, como en Costa Rica, las universidades públicas tienen un mínimo grado de influencia. Determinar qué y cómo se enseña es una cuestión política que tiende a reproducirse en la estructura burocrática del Estado. Así, en Costa Rica el órgano rector es el Consejo Superior de Educación, el cual está compuesto por el ministro del ramo, un exministro -acaso para asegurar la continuidad-, representantes de sindicatos - que son subordinados del ministro- y un solo representante de las universidades estatales. En suma, una composición que garantiza la continuación del status quo contra el cual es muy difícil luchar.

El currículo de los sistemas educativos en los países centroamericanos es muy diferente y no veo ni la instancia ni la voluntad política para elaborar unos planteamientos generales para todos. No es difícil imaginar el origen de esta incapacidad, a pesar de movimientos de integración regional como el Mercado Común Centroamericano o el Tratado de Libre Comercio. Buena parte de lo que se enseñaba en historia -lo que en Costa Rica se denomina Estudios Socialesprovenía del discurso sobre el pasado que justificó a cada Estado-nación, incluyendo los conflictos con los vecinos. ¿Acaso el gobernante del primer liberalismo, héroe por excelencia en Honduras y El Salvador, no fue fusilado en Costa Rica? Obviamente que la historia no es la colección de héroes nacionales, pero ¿cómo enfrentar esos puntos de fricción cuando hay estatuas, calles y efemérides que los recuerdan constantemente, en tanto que carecemos de un proyecto político común?

Por último, creo que hay un problema de comprensión del medio. Dicen que los jóvenes de ahora no leen y eso es mentira: me atrevo a asegurar que no ha habido una generación que lea más en toda la historia. Que lo que leen en el teléfono sean trivialidades es otra cosa, pero que leen nunca ha habido nadie que lea más. Que la calidad de lo que leen no contribuya a su formación es otra cosa totalmente diferente. Esta revolución tecnológica, que nos impide a los legos siquiera imaginar cómo será dentro de un lustro, tiene que ser el medio de incidir en la formación de las futuras generaciones y, obviamente, será algo que deberá explorar la próxima generación.

Nada impide el seguir editando libros en papel, pero sería de una ceguera peligrosa ignorar el poder de las casas editoriales. Los colegas de una universidad pública hicieron una serie de libros de texto para todos los años de secundaria, pero, por presión de un ministro, una autoridad recién electa canceló el proyecto. Nunca fueron oficiales, por lo que ni compitieron con los textos de editoriales privadas, cuyos nombres omito. Estas cada vez añaden más y más elementos para mantener la educación prácticamente en sus manos. Recientemente 
me contaron de una editorial que ahora, incluso prepara no solamente las formas de evaluación sino las formas de presentación de los contenidos por los docentes. En realidad, quien enseña es una especie de empleado de la editorial, pero con salario del Estado.

La elaboración de libros de texto para la enseñanza general básica, que se inició con el que se preparó para El Salvador en un contexto político sorprendente, fue parte de ese "momento de esperanza" en que la comunidad de historiadores centroamericanos deseó proponer que se comprendieran procesos para sustituir héroes y efemérides. Ese momento ya pasó porque la tecnología está en proceso de volver trastos de otra época a los libros de papel, de forma que en el futuro habrá que pensar en medios más apropiados a los medios por los que los jóvenes reciben mensajes y se mantienen vinculados con el Universo.

RH: Pasando a otros temas, cuéntenos acerca de sus nuevos proyectos. ¿Qué temas estás investigando, cómo es que llegaste a esas temáticas?

JAFM: Estoy terminando una historia social de la guerra de 1856, de la cual ya publiqué un artículo sobre la tensión que existió entre la participación como milicianos y las exigencias de la economía. También estoy elaborando una reinterpretación de la incorporación del Partido de Nicoya a Costa Rica, del cual también ya apareció un artículo. Ambos, la "anexión" de Nicoya y la Campaña Nacional 1856-1857, son pilares claves de la ideología nacionalista costarricense y ya era hora de revisarlos.

Por otro lado, ahora estoy iniciándome en un campo nuevo para mí, pero que me llama mucho la atención y que definitivamente tiene una gran importancia, como la tenía la historia social cuando decidimos iniciarla en su momento. Estoy acompañando a colegas más jóvenes a analizar problemas de historia ambiental, en algunos casos vista desde el punto de vista político, en otros, vista más bien desde el punto de vista económico. Lo estoy disfrutando, pues es una temática muy interesante y novedosa que ilumina nuevos aspectos para nuestra comprensión del pasado, especialmente del siglo XX.

Por último, para un público meta más limitado, de unas 500 personas, estoy haciendo una historia de mi familia desde el siglo XVIII. Ha resultado muy satisfactorio pues en archivos españoles, cubanos y costarricenses he encontrado los datos que complementan los escasos registros familiares, que luego enfrenté con las distintas versiones orales que existían sobre el pasado de la familia. Ha resultado complejísimo pues en algunos casos los villanos resultaron no serlo tanto y los "santos" no eran tan merecedores de los altares. La idea es comenzar alrededor de 1790 y terminar cuando murió la última tía abuela en 1967. Tiene que ver no solamente con los libros sobre historia española que me leyeron o leí, 
de los cuales hablamos en la primera pregunta, sino que está vinculada con esa sensación que te deja el ser descendiente de inmigrantes, que siempre te están señalando porque su abuelo vino, porque se casó con su abuela, porque esto o el otro, que te mete esa idea de que existe algo tuyo en otro lado. En algunos casos hay conflictos en la memoria familiar porque existen varias versiones, lo que me obliga a presentarlas todas, aunque señalando cuál considero la más creíble bien sea por la lógica de los procesos históricos o porque existen otras fuentes escritas que la apoyan.

RH: Imaginamos que, viniendo de tu pluma, has desempacado la historia de tu familia que de una forma dice mucho de la historia de Costa Rica.

JAFM: Es posible que haya algún aporte, por lo menos sobre un área periférica como las faldas del volcán Irazú en Cartago, sobre una familia inmigrante que no tuvo acceso al café, pero, aprovechando la coyuntura de la construcción del Canal de Panamá y de la Primera Guerra Mundial, logró hacer el capital suficiente, no solamente para comprar tierra sino también para prestar plata.

RH: Y hace falta más ese tipo de historia familiar. Pareciera que es necesario entrarle a eso, porque se entra a ese nivel de detalle, pero luego se identifica mucho del contexto.

JAFM: Sí, hay aspectos muy simpáticos porque todos tenían grados distintos de humor, desde el bisabuelo a la generación de mi abuelo, y cada uno veía las cosas de una manera diferente. Hay lógicas que van cambiando; por ejemplo, los padrinos de mi abuelo y sus hermanos en España fueron parientes, pero en Costa Rica cambió radicalmente: el parentesco espiritual se usaba para consolidar amistades. En tres migraciones -que se iniciaron con una catástrofe en los viñedos malagueños- y cuatro propiedades pasaron de ser productores de pasas a ser productores de papas.

RH: En el trasfondo de todo esto hay como una reflexión muy profunda sobre cómo se aprende y qué hacemos los que enseñamos. Tiene usted una reflexión amplia sobre este tema, realmente ha sido como el subtexto de lo que hemos estado hablando, de lo que aprendemos y de lo que enseñamos, pues que nos mezclamos un poco, a veces somos la misma persona.

JAFM: Aquí hay un problema. La única persona a la que yo puedo juzgar es a mí mismo. Nunca he visto enseñar a otro desde que fui alumno. Yo digo 
que lo que ha cambiado fundamentalmente no son solamente los medios con los cuales enseñamos, sino el cerebro de los receptores. Nuestra capacidad de concentración en una clase y capacidad de participación, en estos momentos se ven afectadas por esta necesidad que tiene esta generación de estar conectada con una especie de gran placenta universal de información, de la que dependen.

El otro día vi una pirámide de las necesidades humanas. En la base estaba la batería; sobre esta situaron al wi-fi y la comida ocupaba el último estrato. ¡Mientras estén conectados no importa que no coman! Yo en lo personal nunca he podido dividir mi cerebro. Si quiero oír música, oigo música; si quiero leer, leo; pero si yo me pongo en la computadora y pongo música lo que me asusta es cuando suena clic, porque no oí nada. Es un problema en mi cerebro, y desgraciadamente como solo tengo uno, no puedo decir es que este es el cerebro A, debo comportarme como el cerebro B. Ahora esto es una excepción, están con tres o cuatro cosas a la vez: leyendo un libro, haciendo exámenes o prácticas de matemáticas, viendo una telenovela en Internet, contestándole al novio o a la novia por el celular, y por otro teléfono todavía te hablan. Si uno les pregunta: “Estás haciendo algo?”, responden: "No, no estoy haciendo nada”. Es una característica generacional.

Hace años que no enseño, pero por ejemplo yo nunca permití que usaran el celular en mi clase, no porque yo tenía el derecho, sino porque me tenían miedo, gracias a los dioses, yo aprovechaba ese temor para confiscar los celulares y isan se acababa! Después de pensionado, me invitó una profesora a dar una clase y confieso que me quedé con la boca abierta, al ver a todos los alumnos con la atención en las pantallas o hablando. Si a mí me hubieran hecho esto, o me muero de la cirrosis o me quedo sin alumnos, pues no era aceptable para mí. De nuevo el medio, tenemos que pensar en el medio.

RH: Sí, es un desafío muy grande.

JAFM: Siempre me viene a la cabeza, por su carácter visionario, el motto que resume el pensamiento del filósofo canadiense Marshall McLuhan: "El medio es el mensaje". Es algo que hay que pensar muy cuidadosa y profundamente. A veces creo que, por esa forma de comportamiento de los jóvenes actuales, es que todo el sistema educativo está colapsando. Si siempre fue estúpido forzar a chiquitos y adolescentes a permanecer en un aula por seis horas, ahora es simplemente ir contra natura. Esto es algo que afecta a todo el sistema educativo, desde la primaria hasta la universidad.

RH: Ya para terminar y como ha tocado el tema de la educación, ¿qué le diría usted a un joven que está empezando a estudiar historia hoy? 
JAFM: Le repetiría aquella frase atribuida a Albert Einstein: "La imaginación es más importante que el conocimiento". No importa cuánto lea, cuánto intente aplicar una teoría a la realidad, si no tiene capacidad de imaginación para hacerlo creativamente, no va a ser propositivo. Leer tendrá que leer, conocer fuentes es parte de la profesión, y para explicar la realidad tendrá que partir de teorías; pero lo que hace la diferencia es la capacidad de imaginar, de aplicar creativamente.

Nueva York / Heredia, 31 de agosto de 2018 